\title{
BMJ Open Cohort profile: the West Sweden Asthma Study (WSAS): a multidisciplinary population-based longitudinal study of asthma, allergy and respiratory conditions in adults
}

\author{
Bright I Nwaru, ${ }^{1,2}$ Linda Ekerljung, ${ }^{1}$ Madeleine Rådinger, ${ }^{1}$ Anders Bjerg, ${ }^{1}$ \\ Roxana Mincheva, ${ }^{1}$ Carina Malmhäll, ${ }^{1}$ Malin Axelsson, ${ }^{1,3}$ Göran Wennergren, ${ }^{1,4}$ \\ Jan Lotvall, ${ }^{1}$ Bo Lundbäck ${ }^{1}$
}

To cite: Nwaru BI, Ekerljung L, Rådinger $\mathrm{M}$, et al. Cohort profile: the West Sweden Asthma Study (WSAS): a multidisciplinary populationbased longitudinal study of asthma, allergy and respiratory conditions in adults. BMJ Open 2019;9:e027808. doi:10.1136/ bmjopen-2018-027808

Received 8 November 2018 Revised 13 March 2019 Accepted 30 May 2019

Check for updates

(c) Author(s) (or their employer(s)) 2019. Re-use permitted under CC BY-NC. No commercial re-use. See rights and permissions. Published by BMJ.

${ }^{1}$ Krefting Research Centre, Institute of Medicine, Sahlgrenska Academy, University of Gothenburg, Gothenburg, Sweden ${ }^{2}$ Wallenberg Centre for Molecular and Translational Medicine, Institute of Medicine, University of Gothenburg, Gothenburg, Sweden ${ }^{3}$ Department of Care Science, Faculty of Health and Society, Malmö University, Malmö, Sweden

${ }^{4}$ Department of Paediatrics, Institute of Clinical Sciences, Sahlgrenska Academy, University of Gothenburg, Goteborg, Sweden

Correspondence to Dr Bright I Nwaru; bright.nwaru@gu.se

\section{ABSTRACT}

Purpose The West Sweden Asthma Study (WSAS) is a population-representative longitudinal study established to: (1) generate data on prevalence trends, incidence and remission of asthma, allergy and respiratory conditions, (2) elucidate on the risk and prognostic factors associated with these diseases, (3) characterise clinically relevant phenotypes of these diseases and (4) catalyse relevant mechanistic, genomic, genetic and translational investigations.

Participants WSAS comprised of randomly selected individuals aged 16 to 75 years who are followed up longitudinally. The first stage involved a questionnaire survey (>42000 participants) and was undertaken in 2008 and 2016. A random sample (about 8000 ) of participants in the initial survey undergoes extensive clinical investigations every 8 to 10 years (first investigations in 2009 to 2012, second wave currently ongoing). Measurements undertaken at the clinical investigations involve structured interviews, self-completed questionnaire on personality traits, physical measurements and extensive biological samples.

Findings to date Some of our key findings have shown a $54 \%$ increase in the use of asthma medications between the 1990s and 2000s, primarily driven by a five-fold increase in the use of inhaled corticosteroids. About $36 \%$ of asthmatics expressed at least one sign of severe asthma indicator, with differential lung performance, inflammation and allergic sensitisation among asthmatics with different signs of severe asthma. Multi-symptom asthmatics were at greater risk of having indicators of severe asthma. In all adults, being raised on a farm was associated with a decreased risk of allergic sensitisation, rhinitis and eczema, but not asthma. However, among adolescents (ie, those 16 to 20 years of age), being raised on a farm decreased the risk of asthma. Personality traits were associated with both beliefs of asthma medication and adherence to treatment.

Future plans Follow-up of the cohort is being undertaken every 8 to 10 years. The repeated clinical examinations will take place in 2019 to 2022 . The cohort data are currently being linked to routine Swedish healthcare registers for a

\section{Strengths and limitations of this study}

- The West Sweden Asthma Study (WSAS) is a largescale multidisciplinary population-representative longitudinal study on adult asthma and respiratory health, representing one of the largest of such cohorts in Europe.

- WSAS has several ongoing collaborations with investigators across the Nordic countries, with the Obstructive Lung Diseases in Northern Sweden studies, and the FinEsS studies in Finland, Estonia and Sweden and the survey instruments used have been adapted from these ongoing studies.

- With a large sample size, comprehensive measures, and long-term longitudinal design, WSAS provides an opportunity for a continuous generation of contemporary data on the trends in incidence and prevalence of adult asthma and successfully undertaking disease phenotyping.

- With the extensive clinical and molecular investigations being undertaken, WSAS represents one of the unique platforms to undertake cutting-edge mechanistic, genomic, genetic and translational investigations of the underlying pathogenesis of asthma.

- Although the participation rate in WSAS was overall average (with a decline between the surveys in 2008 and 2016), we anticipate, as reflected in current trends in population-based surveys, a continuous decline in response rate over time.

continuous follow-up. Mechanistic, genomic, genetic and translational investigations are ongoing.

\section{INTRODUCTION}

According to the 2015 Global Burden of Disease study, nearly 400 million people across all age groups currently live with asthma globally. ${ }^{1}$ The report also ranked asthma among the 10 causes of disability in 2015, affecting 
people of all ages, sexes and races. ${ }^{1}$ From the latter half of the last century, the prevalence of asthma was seen to be increasing across different parts of the world. ${ }^{2-5}$ While some recent data indicate a levelling off in some parts of the world, particularly in Australia ${ }^{267}$ and some European countries, ${ }^{2-14}$ other evidence suggests a continuing increase in urbanised settings of low- and middle-income countries ${ }^{15}$ and some increase in some parts of Europe, for example, Finland, Italy and Sweden. ${ }^{16-19}$ Much of the available data on asthma prevalence trends have however emanated from children and adolescent populations. There are paucity of data on the prevalence trends in adults, particularly the trends after the $1990 \mathrm{~s}^{2}{ }^{2}$ Well-designed population-representative long-term longitudinal studies are required to obtain contemporary trends in the prevalence of asthma in adults.

Over the last decade, our understanding of the pathogenesis of asthma has been greatly advancing. ${ }^{19-21}$ Contrary to previous understanding, it is now continuously appreciated that asthma is a complex and heterogeneous syndrome with different underlying distinct phenotypes. ${ }^{20-24}$ These phenotypes tend to present with varying clinical pictures, prognosis, risk factors and response to treatment. ${ }^{22-24}$ Through analyses of several children cohorts, common asthma phenotypes have been characterised, including transient wheezing, non-atopic wheezing and IgE-mediated wheezing. ${ }^{25} 26$ In contrast, the lack of well-designed population-representative cohorts has meant that far less knowledge has been gained regarding asthma phenotypes in adults. There are today several partly similar suggested groupings of asthma phenotypes in adults; one of the common approaches has been to group them into three: (1) trigger-induced asthma (eg, occupational asthma, cigarette smoke-induced asthma, exercise-induced asthma), (2) symptom-based asthma (eg, asthma with persistent airflow limitation, adult-onset asthma, obesity-related asthma) and (3) biomarker-based asthma (eg, eosinophilic-associated asthma). ${ }^{23} 252728$ Adult-onset asthma is different from asthma in childhood ${ }^{29}{ }^{30}$ and it is less associated with allergy and atopy, but is often associated with obesity, represents more severe disease, has low remission rate, poor prognosis and faster decline in lung function. ${ }^{30} 31$ Definitive phenotyping of adult asthma will engender better insights into the potential disease mechanisms and will help to identify potentially relevant biomarkers that can aid more targeted treatment. $^{243233}$

The West Sweden Asthma Study (WSAS) ${ }^{13}$ is a large-scale multi-disciplinary population-representative longitudinal study on asthma, which was established in 2008 with the overarching aim of contributing to better understanding of asthma in adults. WSAS has both short-term and longterm goals (figure 1). The short-term goal is to generate data on the trends in prevalence, incidence and remission of asthma, respiratory conditions, chronic obstructive pulmonary disease (COPD) and allergic diseases in adults in the western Swedish population and to elucidate on the risk and prognostic factors associated with these diseases, as well as the patterns in asthma remission. The long-term goals are to: (1) characterise clinically relevant phenotypes of asthma, allergy and respiratory conditions and perform detailed clinical and molecular epidemiological investigations of these conditions and (2) catalyse prevalence and disease burden
Population profiling of asthma
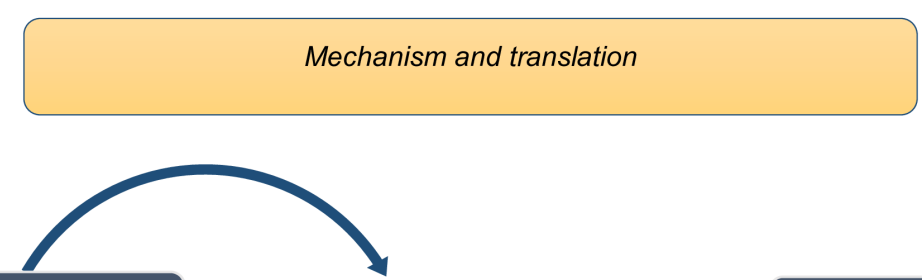

Clinical investigations and asthma phenotyping

-Prevalence

- Demographic risk factors

- Environmental risk factors

- Time trends

-Population burden

-etc

Population surveys

and linkage to

national registers

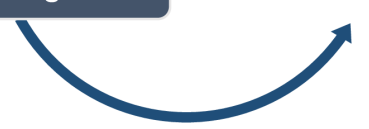

- Incidence

-Asthma phenotypes

- Clinical outcomes and co-

morbidities

-Severe asthma

- Extrisinc \& intrisinc risk

factors

Extensive clinical and

molecular epidemiology

Figure 1 Phases and components of investigations in the West Sweden asthma study. 
WSAS I

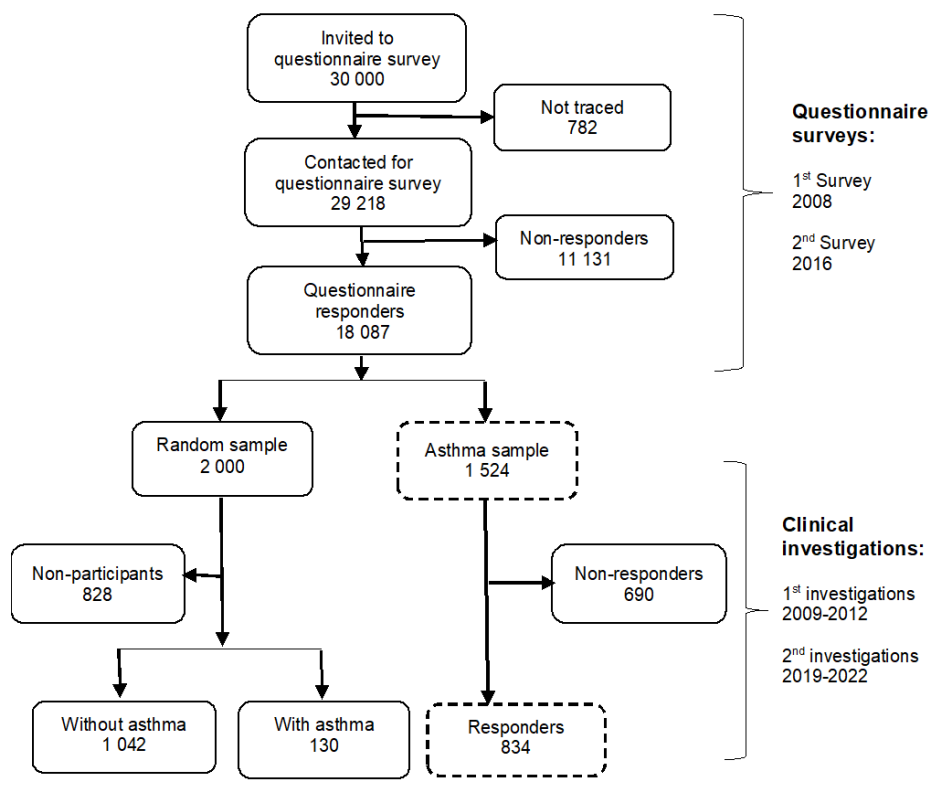

WSAS II

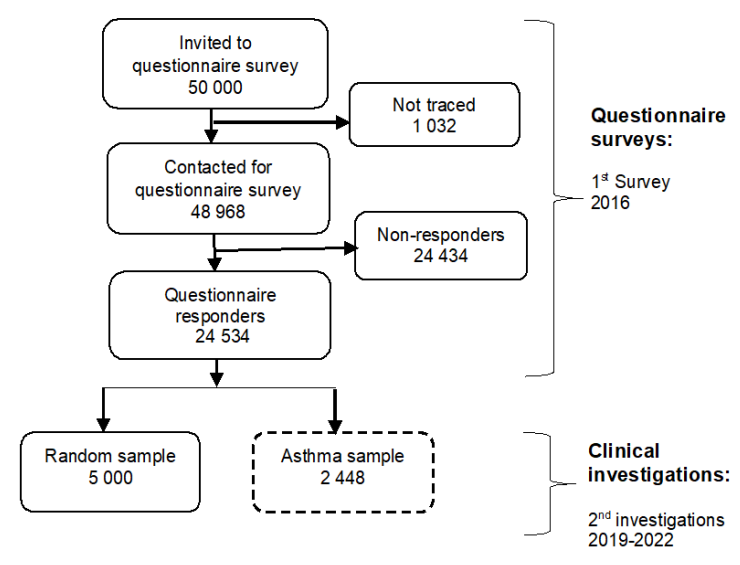

Figure 2 Participants flow in the West Sweden asthma study. WSAS, West Sweden Asthma Study.

relevant mechanistic, genomic, genetic and translational investigations for better understanding of asthma.

\section{COHORT DESCRIPTION \\ Study population}

WSAS involves an initial cross-sectional survey of randomly selected individuals aged 16 to 75 years who are then subsequently followed up longitudinally (figure 2). ${ }^{13} 34$ The first survey (WSAS I) was undertaken in 2008 in which a random sample of 30000 people (representative of the age and sex composition of the study area) were invited. Of the survey participants, excluding those who were not traceable $(\mathrm{n}=782), 18087$ (all 62\%, women 67\%, men $56 \%)$ participated in the study. From the participants, a random sample of 2000 people from all participants and additional 1524 subjects with asthma (altogether 3524 people) were invited to take part in extensive clinical investigations. Of those invited, 2006 participated in the clinical investigations, which took place between 2009 and 2012. ${ }^{33}$ A second survey (WSAS II) was carried out in 2016 in which a random sample of 50000 people of the same age group as in WSAS I were invited to take part in the study. The sampling base (areas covered) in WSAS II did not fully overlap with WSAS I; moreover, each survey constitutes different participants. In total, 24534 (all $50 \%$, women $56 \%$, men $46 \%$ ) of the 50000 invited participated in the study. About 2200 of those that participated in WSAS II have current asthma; in addition to these, 4000 random sample from all participants (altogether 6200 people) will be invited to take part in the extensive clinical phase of the study. The goal of WSAS II was to study prevalence change and also to expand the overall study base and to enhance the number of participants included in subsequent clinical phases of the study.

\section{Cohort follow-up}

Those who participated in WSAS I in 2008 were invited for a follow-up survey in 2016. In addition, those who took part in the clinical investigations between 2009 and 2012 have been invited and are currently undergoing follow-up clinical investigations. Our goal is to capture incident cases of the outcomes, investigate the role of baseline risk factors in disease incidence and to measure changes in clinical outcomes post-baseline. Continuous follow-up of the cohort will continue, and this is planned to take place at approximately 8 to 10 years, at which time measurable changes should have occurred in the study population. Those who participated in WSAS II will be similarly followed and investigated as those in WSAS I. We also obtained consent from participants and ethical approval to link the study data to routine healthcare registers for a continuous follow-up. Linkable registers include the National Board of Health and Welfare (register of causes of deaths, hospitalisations, primary healthcare and medication prescriptions), Statistics Sweden (containing information on demographics) and the Swedish Health Insurance Authority (register of working life, sickness leaves and retirement).

\section{Data collection}

Table 1 contains a summary of the measurements undertaken at different phases of the study. At baseline, participants received a postal self-completed questionnaire that contained questions that have been previously used in the Obstructive Lung Diseases in Northern Sweden (OLIN $),{ }^{35}{ }^{36}$ the Global Allergy and Asthma European Network (GA $\left.{ }^{2} L E N\right)$ studies, the FinEsS studies in Finland, Estonia and Sweden ${ }^{37} 38$ and the European Community Respiratory Health Survey (ECRHS). ${ }^{39}$ The questions adapted from OLIN and ECRHS focused on asthma, 
Table 1 Main measurements at different phases of the West Sweden asthma study

\begin{tabular}{ll}
\hline Phase & Measurements \\
\hline Baseline survey: & Self-completed questionnaire only: \\
2008 (WSAS I); & Self-reported asthma, allergy, respiratory symptoms, medication use \\
2016 (WSAS I and WSAS II) & Self-reported socio-economic status; smoking habits; and airborne, occupational and \\
& environmental exposures
\end{tabular}

First clinical follow-up:

2009-2012;

2018-ongoing

\section{Structured clinical interview and self-administered questionnaire: \\ Questions about asthma, allergy, respiratory symptoms, medication use \\ beliefs about asthma medications depression and anxiety and quality of life \\ Anthropometric measures: height and weight measurements \\ Clinical examinations: \\ Haemoglobin saturation; blood pressure; blood samples; nasal lavage; skin prick test; specific immunoglobulin E; differential cell counts in blood; component resolved diagnostics; body fat; muscle mass; metabolic age (impedance); hand strength with grip pit; forced impulse oscillometry; forced oscillometry technique (small airways); diffusion capacity; functional residual capacity and total lung capacity; dynamic and bronchoschopy including bronchial biopsies, bronchial lavage and bronchial brushings.}

Other questions about smoking habits, food intolerance, self-efficacy; personality traits; spirometry (Jaeger's MasterScope, methacholine test); exhaled nitric oxide. Other clinical measurements* are: induced sputum, nasal biopsies, nasal swabs for virus determination

$\begin{array}{ll}\text { Ongoing/planned: 2019- } & \text { Proteomics (conventional proteomics and mass cytometry; CyTOF)* } \\ & \text { Genomics* } \\ & \text { Transcriptomics (ie, RNA and microRNA analysis) }{ }^{*} \\ & \text { Linkage to national healthcare registers }\end{array}$

${ }^{*}$ Carried out in a subpopulation of those that were clinically examined.

rhinitis, chronic bronchitis/COPD/emphysema, respiratory symptoms, use of asthma medication and potential risk factors, including smoking habits, family history of respiratory diseases, type of occupation, occupational and environmental exposures, co-morbidities and socio-economic status. The $\mathrm{GA}^{2} \mathrm{LEN}$ questionnaire was used to add detailed questions about rhinitis and eczema. The applicable sections of the questionnaire were translated into Swedish before use in the study. A sample ECRHS questionnaire is publicly available at http://www.ecrhs. org/Quests/ECRHSIImainquestionnaire.pdf. At the clinical investigations, a detailed structured interview is conducted, asking questions about presence of asthma, asthma symptoms and exacerbations, use of medications, healthcare use, obstructive and non-obstructive diseases, smoking habits, asthma triggers, virus-induced exacerbations and food intolerance. A self-completed questionnaire is also carried out to assess issues of health psychology, asking questions related to self-efficacy, personality traits, depression and anxiety and quality of life. The interview is followed by physical examinations including mainly lung function measurements with dynamic spirometry and in subsamples lung volumes, furthermore bronchial provocation test with methacholine, fraction of exhaled nitric oxide and measurement of various biological and blood samples including allergy testing with specific IgE, and skin prick tests. Other planned measurements will include proteomics, transcriptomics, genomics, genetics and linkage to Swedish population registers.

\section{Patient and public involvement}

There was no patient or public involvement in this study.

\section{Findings to date}

Population characteristics

Table 2 shows the distribution of baseline background characteristics of the study population by age and sex. Up to the age of 60 years, more females than males had university education in both WSAS I (2008) and WSAS II (2016) surveys. While the proportion of current smokers was higher in females than males in the youngest age group ( $\leq 30$ years) in 2008 , the proportion of current smokers was similar between males and females in 2016. Across all age groups, more males than females were exposed to gas and fumes at work place both in 2008 and 2016. The proportion of those raised on a farm was similar between males and females in both surveys and the proportion increased by age. More females than males in both surveys reported that they had a family history of allergy or asthma.

\section{Key findings}

The following findings are based only in WSAS I as analyses of WSAS II are currently ongoing. The following constitute the definitions used for the respective outcomes for which findings are reported below: Physician-diagnosed asthma was defined based on a positive response to the question: 'Have you been diagnosed as having asthma by a doctor?' Current asthma was defined as ever had asthma or diagnosed with asthma by a doctor and at least 1 of the 


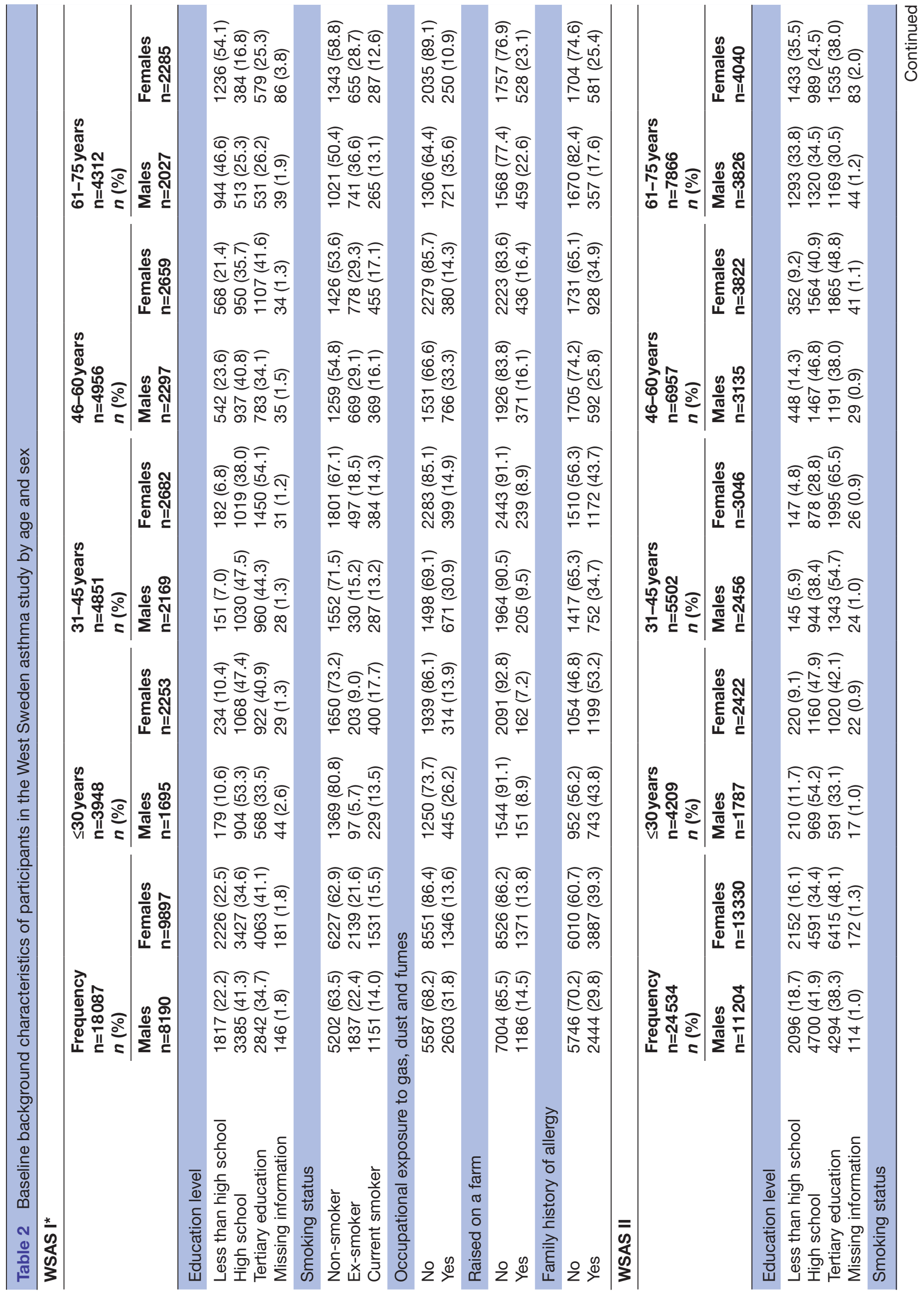

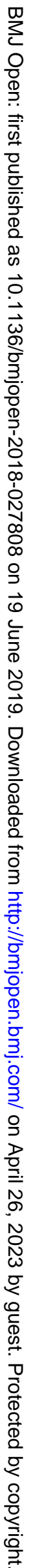




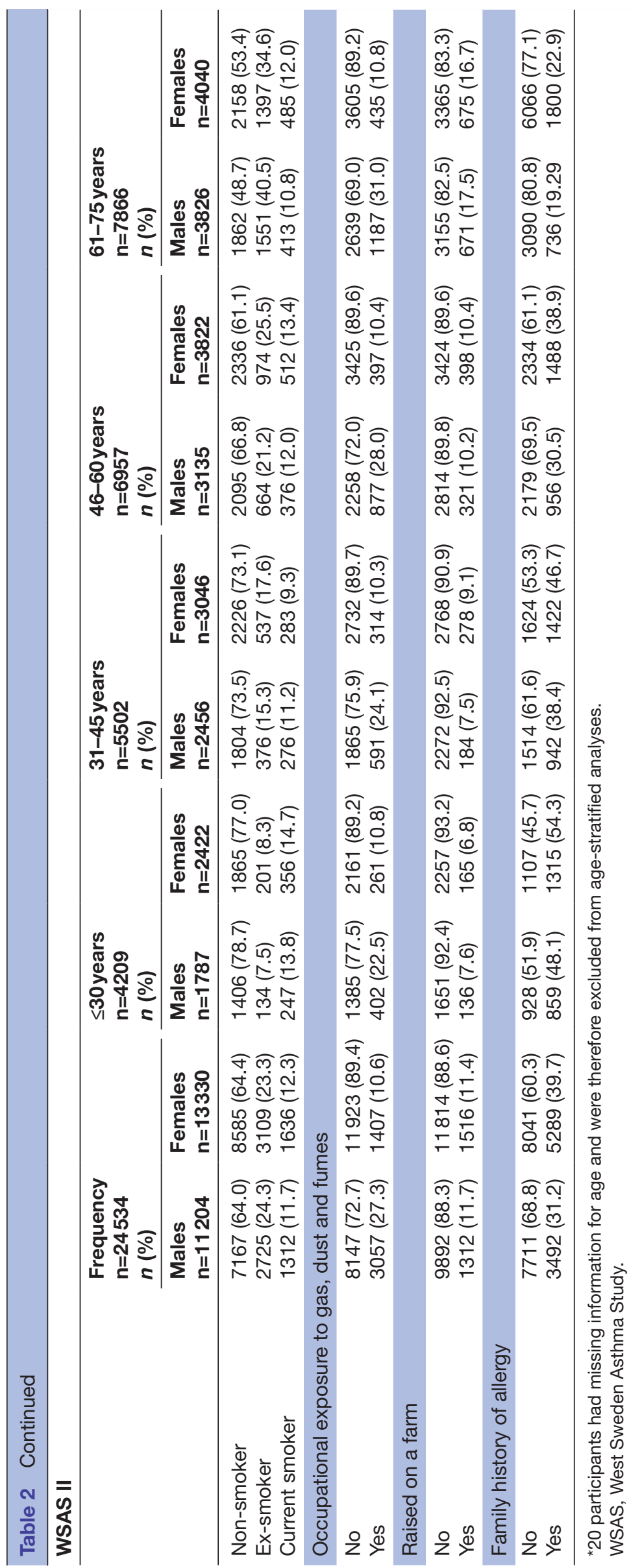


following: reported use of asthma medication, or recurrent wheeze, or attacks of shortness of breath during the last 12 months. Current allergic rhinitis was defined as having had sneezing, runny nose or nasal blocking apart from colds during the last 12 months and having these nasal symptoms occurring simultaneously with itching and running eyes. The definitions of eczema, which we have previously used, ${ }^{40}$ were based on answers to the following questions: Itchy rash: 'Have you ever had an itchy rash which was coming and going for at least 6 months?' Hand eczema only: 'Does this (itchy rash) only affect your hands?' Current atopic eczema: 'Have you had this itchy rash in the last 12 months?' Eczema ever. 'Have you ever had eczema or any kind of skin allergy?' By comparing to a previous study performed in the study area in 1990, we determined that while the prevalence of most respiratory symptoms, including wheeze, sputum production and long-standing cough, substantially decreased by 2008 , the prevalence of physician=diagnosed asthma $(6 \%$ in 1990 vs $8 \%$ in 2008) remained relatively stable. ${ }^{13}$ However, during the same period, there was a $54 \%$ increase in the use of asthma medications, which was primarily driven by a five-fold $(1.5 \%$ to $7.7 \%)$ increase in the use of inhaled corticosteroids. ${ }^{34}$ We have also shown that individuals with multi-symptom asthma (ie, report of concurrent presence of at least five asthma symptoms, present in $2 \%$ of the population) were at greater risk of having morbidity indicators of asthma severity, including lower forced expiratory volume in one second $\left(\mathrm{FEV}_{1}\right)$, higher fractional exhaled nitric oxide (FeNO) levels, elevated hyper-responsiveness, nasal blockage and chronic rhinosinusitis compared with those with less asthma symptoms. ${ }^{4142}$ By constructing different degrees of asthma severity based on the number of signs of severe asthma indicators, our recent results showed that about $36 \%$ of asthmatics expressed at least one sign of severe asthma indicator and that clinical measures of lung performance, inflammation and allergic sensitisation differ among asthmatics with different signs of severe asthma. ${ }^{43}$

Based on our risk factor analyses (table 3) of WSAS I only (analyses of WSAS II are ongoing and not included in these results), we have shown that female gender (compared with males) was associated with an increased risk of current asthma and eczema, but not allergic rhinitis. ${ }^{43}$ Having concomitant family history of asthma and allergic rhinitis (compared no family history of either conditions) was associated with an increased risk of current asthma and allergic rhinitis, but not current eczema. ${ }^{44}$ A family history of allergic rhinitis only was also associated with an increased risk of allergic rhinitis, but not asthma and eczema; a family history of asthma only was not associated with asthma, rhinitis or eczema (table 3) ${ }^{44}$ Being raised on a farm was associated with a decreased risk of allergic sensitisation, allergic rhinitis and eczema ${ }^{44-46}$; while it was not associated with asthma among all adults. ${ }^{44}$ However, there was a decreased risk of asthma among adolescents (ie, those 16 to 20 years of age).$^{47} \mathrm{In}$ that young age group, being raised on a farm significantly reduced the likelihood of using asthma medicine, OR 0.1 (0.02 to 0.95$).{ }^{47}$ Obese individuals (compared with normal weight) was associated with the risk of asthma and allergic rhinitis, but not eczema. ${ }^{44}$ Having at least one sibling was associated with an increased risk of asthma, but not allergic rhinitis, whereas, having two more siblings was associated with a decreased risk of eczema. ${ }^{44}$ The strongest risk factor for eczema was family history of both asthma and allergy. ${ }^{40}$ Sensitisation to airborne allergens was associated with an increased risk of asthma, allergic rhinitis and eczema. Finally, exposure to gas, dust or fumes at work place was associated with an increased risk of asthma and eczema, but not allergic rhinitis (table 3). ${ }^{44}$ The risk factors observed for asthma were similarly seen for aspirin-intolerant and aspirin-tolerant asthma. ${ }^{48} \mathrm{We}$ also showed that personality traits were associated with both beliefs of asthma medication and adherence to treatment, which indicate that individual differences are important in efforts to improve adherence. ${ }^{49}$ Ongoing mechanistic studies include analysis of airway and blood samples from well-defined asthma groups where we more specifically investigate the transcriptome profiles (ie, mRNA and microRNA expression). In addition, we are in collaboration the national mass cytometry facility SciLifeLab in Solna, Stockholm, Sweden, to develop a platform with approximately 40 cell surface or intracellular markers that will be analysed from asthmatics samples within WSAS.

\section{Strengths and limitations of this study}

Nordic countries have had a long tradition of implementing a systematic research approach in understanding chronic diseases and their underlying mechanisms: usually starting from population epidemiological studies to clinical investigations, and further to mechanistic investigations and translation. The establishment of population-wide disease and health registers and excellent and well-characterised longitudinal cohorts involving all age groups, with various social, economical and biological measurements, has continuously allowed multidisciplinary investigations into different chronic diseases. ${ }^{5051}$ Some examples of these studies include the Nordic Medical Birth Registers, ${ }^{51}{ }^{52}$ the Copenhagen City Heart Study, ${ }^{53}$ the Hordaland Health Study, ${ }^{54}$ the OLIN studies $^{55}$ and the European Community Respiratory Health Survey, ${ }^{56}$ which are still ongoing, have provided longitudinal data, including on respiratory health, for the past 30 to 50 years. Now, WSAS, representing one example of these population cohort studies, represents one of the largest population-representative studies on asthma in Europe.

The multidisciplinary nature of WSAS - integrating aspects of population epidemiology, clinical and molecular epidemiology, mechanistic investigations and various translational research approaches - establishes it as a major platform to significantly advance clearer understanding of adult asthma, respiratory conditions and allergy and their consequent burden to the society. With 
Table 3 Key results of risk factors for asthma, allergic rhinitis and atopic eczema reported from the West Sweden asthma study

\begin{tabular}{|c|c|c|c|}
\hline \multirow[b]{2}{*}{ Risk factor } & \multicolumn{3}{|c|}{ Adjusted estimates* } \\
\hline & $\begin{array}{l}\text { Current asthma† } \\
\text { OR }(95 \% \mathrm{Cl})\end{array}$ & $\begin{array}{l}\text { Current allergic rhinitis } \neq \\
\text { OR }(95 \% \mathrm{Cl})\end{array}$ & $\begin{array}{l}\text { Current eczema§ } \\
\text { OR }(95 \% \mathrm{Cl})\end{array}$ \\
\hline \multicolumn{4}{|c|}{ 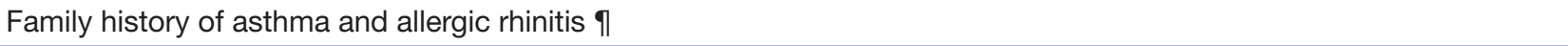 } \\
\hline $\begin{array}{l}\text { None } \\
\text { Asthma only } \\
\text { Allergic rhinitis only } \\
\text { Both asthma and allergic rhinitis }\end{array}$ & $\begin{array}{l}1 \\
1.29(0.55 \text { to } 3.04) \\
1.16(0.66 \text { to } 2.03) \\
4.33(2.57 \text { to } 7.30)\end{array}$ & $\begin{array}{l}1 \\
0.61(0.34 \text { to } 1.10) \\
2.58(1.79 \text { to } 3.72) \\
2.76(1.77 \text { to } 4.31)\end{array}$ & $\begin{array}{l}1 \\
1.45(0.72 \text { to } 2.94) \\
1.25(0.77 \text { to } 2.04) \\
1.61(0.94 \text { to } 2.76)\end{array}$ \\
\hline Raised on a farm ${ }^{56}$ & $0.96(0.52$ to 1.77$)$ & $0.64(0.42$ to 0.96$)$ & $0.51(0.27$ to 0.99$)$ \\
\hline \multicolumn{4}{|l|}{ Body mass index } \\
\hline $\begin{array}{l}\text { Normal }\left(20-25 \mathrm{~kg} / \mathrm{m}^{2}\right) \\
\text { Underweight }\left(<20 \mathrm{~kg} / \mathrm{m}^{2}\right) \\
\text { Overweight }\left(25-30 \mathrm{~kg} / \mathrm{m}^{2}\right) \\
\text { Obese }\left(>30 \mathrm{~kg} / \mathrm{m}^{2}\right)\end{array}$ & $\begin{array}{l}1 \\
0.95(0.36 \text { to } 2.55) \\
1.04(0.65 \text { to } 1.67) \\
1.95(1.13 \text { to } 3.36)\end{array}$ & $\begin{array}{l}1 \\
1.42(0.74 \text { to } 2.71) \\
1.04(0.77 \text { to } 1.41) \\
2.30(1.53 \text { to } 3.46)\end{array}$ & $\begin{array}{l}1 \\
1.00(0.44 \text { to } 2.30) \\
1.02(0.68 \text { to } 1.54) \\
1.34(0.80 \text { to } 2.24)\end{array}$ \\
\hline $\begin{array}{l}0 \\
1 \\
2 \text { or more }\end{array}$ & $\begin{array}{l}1 \\
3.09(1.25 \text { to } 7.63) \\
2.51(1.02 \text { to } 6.15)\end{array}$ & $\begin{array}{l}1 \\
1.16(0.74 \text { to } 1.81) \\
1.15(0.74 \text { to } 1.79)\end{array}$ & $\begin{array}{l}1 \\
0.72(0.42 \text { to } 1.24) \\
0.55(0.32 \text { to } 0.94)\end{array}$ \\
\hline Allergic sensitisation ${ }^{57}$ & $4.11(2.71$ to 6.25$)$ & 5.11 (3.77 to 6.93$)$ & $1.26(0.85$ to 1.85$)$ \\
\hline Exposure to gas, dust or fumes at work & 1.85 (1.20 to 2.87$)$ & $1.03(0.76$ to 1.41$)$ & 2.08 (1.40 to 3.08$)$ \\
\hline
\end{tabular}

${ }^{*}$ Respective to each outcome, the estimates adjusted for age, gender, family history of asthma and rhinitis, exposure to gas and gas fumes at work place, body mass index, number of siblings, daycare attendance during childhood and being raised on a farm.

†Current asthma was defined as follows: ever had asthma or ever diagnosed with asthma by a physician and at least one of: reported use of asthma medication, or recurrent wheeze, or attacks of shortness of breath during the last 12 months.

$\ddagger$ Allergic rhinitis was defined as follows: having had sneezing, runny nose or nasal blocking apart from colds during the last 12 months and having these nasal symptoms occurred simultaneously with itching and running eyes'.

§Defined as having ever had recurrent itchy rash for at least 6 months and having had itchy rash during the last 12 months.

ๆReported in Rönmark et al. Different risk factor patterns for adult asthma, rhinitis and eczema: results from West Sweden Asthma Study. Clin Transl Allergy 2016; 6:28.

${ }^{\star \star}$ Reported in Eriksson, et al. Growing up on a farm leads to lifelong protection against allergic rhinitis. Allergy 2010; 65: $1397-1403$. ††Allergic sensitisation defined as serum immunoglobulin E to ImmunoCAP Phadiatop $\geq 0.35 \mathrm{KU} / 1$ to at least one of the following 11 airborne allergens: timothy grass, birch, mugwort, olive, parietaria, cat, dog, horse, Dermatophagoides pteronyssinus, D. farinae and Cladosporium herbarum.

the extensive clinical and molecular investigations being undertaken, WSAS represents one of the unique platforms to undertake cutting-edge investigations of the underlying pathogenesis of asthma, involving detailed characterisation of the phenotypes, thereby potentially supporting more targeted therapy and personalised clinical decision-making. Both size of the study and comprehensiveness of measurements are of great significance in successful asthma phenotyping. Constituting a random sample of the population, findings from WSAS can be generalised to adult population of western Sweden. The survey instruments and procedures used in WSAS, having being largely adapted from other national and international population and clinical studies across Europe, ensures that the internal validity of the study is greatly enhanced, thus enabling direct comparison of our estimates to the findings from those studies both in time and space. $^{20}$ The main limitation of this study is the anticipated decline in participation rate over time. Although the participation rate in WSAS was overall average (with a decline between the survey in 2008 and 2016), current trends in population-based surveys also show a continuous decline in response rate over time ${ }^{57}$ Furthermore, as the study primarily focused on asthma, clinical examination of the nose and skin was not performed.

\section{COLLABORATION}

We welcome discussions from researchers on collaborative projects that will involve the use of WSAS. Currently such collaborations have been established with investigators across the Nordic countries, with the OLIN study and the FinEsS studies. We are also working towards developing a secure database for hosting data continuously generated from WSAS. The ultimate goal is that, in due course, with the necessary permission processes in place, collaborators can gain access to the data for research.

Acknowledgements The authors are grateful to the research assistants/SRNs Helén Törnqvist, Maryanne Raneklint, Lina Rönnebjerg and Lotte Edvardsson, 
University of Gothenburg, for performing the major part of the data collection and to Eva-Marie Romell for administrative support. BN acknowledges the support of Knut and Alice Wallenberg Foundation and the Wallenberg Centre for Molecular and Translational Medicine, University of Gothenburg.

Contributors Designed the study (BL, JL, LE). Responsible for the study database (LE, BN, MR). Participated in data collection (BL, JL, LE, MR, RM, GW, CM, MA, $A B)$. Planned and executed the statistical analyses and drafted the manuscript (BN, BL, LE, RM, GW, AB). All authors participated in data interpretation, writing of the manuscript and review the data presented. All authors approved the final manuscript.

Funding The study is funded by the VBG Group Herman Krefting Foundation on Asthma and Allergy. Additional support has been received mainly from the Swedish Heart Lung Foundation, the health authorities of the West Gothia Region, the Varrdal Foundation and the Swedish Research Council. The views expressed in this paper are those of the authors and not those of the funders.

Competing interests None declared.

Patient consent for publication Not required.

Ethics approval The study and its substudies have been approved by the local EthicsCommittee at the University of Gothenburg.

Provenance and peer review Not commissioned; externally peer reviewed.

Data sharing statement Data collection is still ongoing and cannot be shared at the moment. Please see contacts below for those would want to know more about the study and would like to collaborate. We are working towards developing a full website that will be dedicated to the WSAS, but summarised descriptions are provided at the website of the Krefting Research Centre, University of Gothenburg, which hosts WSAS, at https://krefting.gu.se/KRC/research. For the meantime, interested researchers should send their enquiries to: linda.ekerljung@lungall.gu. se; bright.nwaru@gu.se; madeleine.radinger@lungall.gu.se.

Open access This is an open access article distributed in accordance with the Creative Commons Attribution Non Commercial (CC BY-NC 4.0) license, which permits others to distribute, remix, adapt, build upon this work non-commercially, and license their derivative works on different terms, provided the original work is properly cited, appropriate credit is given, any changes made indicated, and the use is non-commercial. See: http://creativecommons.org/licenses/by-nc/4.0/.

\section{REFERENCES}

1 GBD. Disease and Injury Incidence and Prevalence Collaborators. Global, regional, and national incidence, prevalence, and years lived with disability for 310 diseases and injuries. Lancet 2015;2016:1545-602.

2 Lundbäck B, Backman $\mathrm{H}$, Lötvall J, et al. Is asthma prevalence still increasing? Expert Rev Respir Med 2016;10:39-51.

3 Woolcock AJ. The problem of asthma worldwide. Eur Respir Rev 1991;1:361-8.

4 Lundbäck B. Epidemiology of rhinitis and asthma. Clin Exp Allergy 1998;28(S2):3-10.

5 Anderson HR, Gupta R, Strachan DP, et al. 50 years of asthma: UK trends from 1955 to 2004. Thorax 2007;62:85-90.

6 Robertson CF, Roberts MF, Kappers JH. Asthma prevalence in Melbourne schoolchildren: have we reached the peak? Med J Aust 2004;180:273-6.

7 Toelle BG, Ng K, Belousova E, et al. Prevalence of asthma and allergy in schoolchildren in Belmont, Australia: three cross sectional surveys over 20 years. BMJ 2004;328:386-7.

8 Devenny A, Wassall H, Ninan T, et al. Respiratory symptoms and atopy in children in Aberdeen: questionnaire studies of a defined school population repeated over 35 years. BMJ 2004;329:489-90.

9 Ng Man Kwong G, Proctor A, Billings C, et al. Increasing prevalence of asthma diagnosis and symptoms in children is confined to mild symptoms. Thorax 2001;56:312-4.

10 Anderson HR, Ruggles R, Strachan DP, et al. Trends in prevalence of symptoms of asthma, hay fever, and eczema in 12-14 year olds in the British Isles, 1995-2002: questionnaire survey. BMJ 2004;328:1052-3.

11 Braun-Fahrländer C, Gassner M, Grize L, et al. No further increase in asthma, hay fever and atopic sensitisation in adolescents living in Switzerland. Eur Respir J 2004;23:407-13.

12 Zöllner IK, Weiland SK, Piechotowski I, et al. No increase in the prevalence of asthma, allergies, and atopic sensitisation among children in Germany: 1992-2001. Thorax 2005;60:545-8.
13 Lötvall J, Ekerljung L, Rönmark EP, et al. West Sweden Asthma Study: prevalence trends over the last 18 years argues no recent increase in asthma. Respir Res 2009;10:94.

14 Hicke-Roberts A, Åberg N, Wennergren G, et al. Allergic rhinoconjunctivitis continued to increase in Swedish children up to 2007, but asthma and eczema levelled off from 1991. Acta Paediatr 2017:106:75-80.

15 Ma Y, Zhao J, Han ZR, et al. Very low prevalence of asthma and allergies in schoolchildren from rural Beijing, China. Pediatr Pulmonol 2009;44:793-9.

16 Backman H, Räisänen P, Hedman L, et al. Increased prevalence of allergic asthma from 1996 to 2006 and further to 2016-results from three population surveys. Clin Exp Allergy 2017;47:1426-35.

17 Kainu A, Pallasaho P, Piirilä $P$, et al. Increase in prevalence of physician-diagnosed asthma in Helsinki during the Finnish Asthma Programme: improved recognition of asthma in primary care? A cross-sectional cohort study. Prim Care Respir J 2013;22:64-71.

18 de Marco R, Cappa V, Accordini S, et al. Trends in the prevalence of asthma and allergic rhinitis in Italy between 1991 and 2010. Eur Respir J 2012;39:883-92.

19 Borna E, Nwaru BI, Bjerg A, et al. Changes in the prevalence of asthma and respiratory symptoms in western Sweden between 2008 and 2016. Allergy. In Press. 2019.

20 Holgate ST. Pathophysiology of asthma: what has our current understanding taught us about new therapeutic approaches? J Allergy Clin Immunol 2011;128:495-505.

21 Holgate ST. Asthma: a simple concept but in reality a complex disease. Eur J Clin Invest 2011;41:1339-52.

22 Borish L, Culp JA. Asthma: a syndrome composed of heterogeneous diseases. Ann Allergy Asthma Immunol 2008;101:1-9.

23 Hekking PP, Bel EH. Developing and emerging clinical asthma phenotypes. J Allergy Clin Immunol Pract 2014;2:671-80.

24 Siroux V, Garcia-Aymerich J. The investigation of asthma phenotypes. Curr Opin Allergy Clin Immunol 2011;11:393-9.

25 Carlsen KCL, Pijnenburg M. Identification of asthma phenotypes in children. Breathe 2011;8:38-44.

26 Stein RT, Martinez FD. Asthma phenotypes in childhood: lessons from an epidemiological approach. Paediatr Respir Rev 2004;5:155-61.

27 Moore WC, Meyers DA, Wenzel SE, et al. Identification of asthma phenotypes using cluster analysis in the Severe Asthma Research Program. Am J Respir Crit Care Med 2010;181:315-23.

28 Wenzel SE. Asthma phenotypes: the evolution from clinical to molecular approaches. Nat Med 2012;18:716-25.

29 Gibson PG, McDonald VM, Marks GB. Asthma in older adults. Lancet 2010;376:803-13.

30 de Nijs SB, Venekamp LN, Bel EH. Adult-onset asthma: is it really different? Eur Respir Rev 2013;22:44-52.

31 Fingleton J, Travers J, Williams M, et al. Treatment responsiveness of phenotypes of symptomatic airways obstruction in adults. J Allergy Clin Immunol 2015:136:601-9.

32 Rönmark E, Andersson C, Nyström L, et al. Obesity increases the risk of incident asthma among adults. Eur Respir J 2005;25:282-8.

33 Brusselle GG, Kraft M. Trustworthy guidelines on severe asthma thanks to the ERS and ATS. Eur Respir J 2014;43:315-8.

34 Ekerljung L, Bjerg A, Bossios A, et al. Five-fold increase in use of inhaled corticosteroids over 18 years in the general adult population in west Sweden. Respir Med 2014;108:685-93.

35 Rönmark E, Lundbäck B, Jönsson E, et al. Incidence of asthma in adults--report from the Obstructive Lung Disease in Northern Sweden Study. Allergy 1997:52:1071-8.

36 Rönmark E, Jönsson E, Lundbäck B. Remission of asthma in the middle aged and elderly: report from the Obstructive Lung Disease in Northern Sweden study. Thorax 1999;54:611-3.

37 Pallasaho P, Lindström M, Põlluste J, et al. Low socio-economic status is a risk factor for respiratory symptoms: a comparison between Finland, Sweden and Estonia. Int J Tuberc Lung Dis 2004;8:1292-300.

38 Lindström M, Kotaniemi J, Jönsson E, et al. Smoking, respiratory symptoms, and diseases : a comparative study between northern Sweden and northern Finland: report from the FinEsS study. Chest 2001;119:852-61.

39 Burney PGJ, Luczynska C, Chinn S, et al. The European Community Respiratory Health Survey. Eur Respir J 1994;7:954-60.

40 Rönmark EP, Ekerljung L, Lötvall J, et al. Eczema among adults: prevalence, risk factors and relation to airway diseases. Results from a large-scale population survey in Sweden. Br J Dermatol 2012;166:1301-8.

41 Lötvall J, Ekerljung L, Lundbäck B. Multi-symptom asthma is closely related to nasal blockage, rhinorrhea and symptoms of chronic 
rhinosinusitis-evidence from the West Sweden Asthma Study. Respir Res 2010;11:163.

42 Ekerljung L, Bossios A, Lötvall J, et al. Multi-symptom asthma as an indication of disease severity in epidemiology. Eur Respir $J$ 2011;38:825-32.

43 Mincheva R, Ekerljung L, Bossios A, et al. High prevalence of severe asthma in a large random population study. J Allergy Clin Immunol 2018;141:2256-64.

44 Rönmark EP, Ekerljung L, Mincheva R, et al. Different risk factor patterns for adult asthma, rhinitis and eczema: results from West Sweden Asthma Study. Clin Transl Allergy 2016;6:28.

45 Eriksson J, Ekerljung L, Lötvall J, et al. Growing up on a farm leads to lifelong protection against allergic rhinitis. Allergy 2010;65:1397-403.

46 Bjerg A, Ekerljung L, Eriksson J, et al. Increase in pollen sensitization in Swedish adults and protective effect of keeping animals in childhood. Clin Exp Allergy 2016;46:1328-36.

47 Wennergren G, Ekerljung L, Alm B, et al. Asthma in late adolescence-farm childhood is protective and the prevalence increase has levelled off. Pediatr Allergy Immunol 2010;21:806-13.

48 Eriksson J, Ekerljung L, Bossios A, et al. Aspirin-intolerant asthma in the population: prevalence and important determinants. Clin Exp Allergy 2015;45:211-9.

49 Axelsson M, Cliffordson C, Lundbäck B, et al. The function of medication beliefs as mediators between personality traits and adherence behavior in people with asthma. Patient Prefer Adherence 2013;7:1101-9.

50 Furu K, Wettermark B, Andersen M, et al. The Nordic countries as a cohort for pharmacoepidemiological research. Basic Clin Pharmacol Toxicol 2010;106:86-94.

51 Langhoff-Roos J, Krebs L, Klungsøyr K, et al. The Nordic medical birth registers--a potential goldmine for clinical research. Acta Obstet Gynecol Scand 2014;93:132-7.

52 Gissler M, Louhiala P, Hemminki E. Nordic Medical Birth Registers in epidemiological research. Eur J Epidemiol 1997;13:169-75.

53 Schnohr P, Jensen GB, Lange P, et al. The Copenhagen City Heart Study. Eur Heart J Suppl 2011;3:H1-83.

54 Vikse BE, Vollset SE, Tell GS, et al. Distribution and determinants of serum creatinine in the general population: the Hordaland Health Study. Scand J Clin Lab Invest 2004;64:709-22.

55 Lundbäck B, Nyström L, Rosenhall L, et al. Obstructive lung disease in northern Sweden: respiratory symptoms assessed in a postal survey. Eur Respir J 1991;4:257-66.

56 Burney PG, Luczynska C, Chinn S, et al. The European Community Respiratory Health Survey. Eur Respir J 1994;7:954-60.

57 Mindell JS, Giampaoli S, Goesswald A, et al. Sample selection, recruitment and participation rates in health examination surveys in Europe--experience from seven national surveys. BMC Med Res Methodol 2015;15:78 